Management of Disease in Wild Mammals 
Richard J. Delahay - Graham C. Smith

Michael R. Hutchings

Editors

\section{Management of Disease in Wild Mammals}

黛 Springer 
Editors

Richard J. Delahay

Central Science Laboratory

Wildlife Disease Ecology Team

Sand Hutton, York

YO41 1LZ, United Kingdom
Graham C. Smith

Central Science Laboratory

Wildlife Disease Ecology Team

Sand Hutton, York

YO41 1LZ, United Kingdom

Michael R. Hutchings

Scottish Agricultural College (SAC)

Disease Systems Team

West Mains Road, Edinburgh

EH9 3JG, United Kingdom

ISBN: 978-4-431-77133-3

Springer Tokyo Berlin Heidelberg New York

e-ISBN: 978-4-431-77134-0

DOI: $10.1007 / 978-4-431-77134-0$

Library of Congress Control Number: 2008938542

(C) Springer 2009

Printed in Japan

This work is subject to copyright. All rights are reserved, whether the whole or part of the material is concerned, specifically the rights of translation, reprinting, reuse of illustrations, recitation, broadcasting, reproduction on microfilms or in other ways, and storage in data banks.

The use of registered names, trademarks, etc. in this publication does not imply, even in the absence of a specific statement, that such names are exempt from the relevant protective laws and regulations and therefore free for general use.

Printed on acid-free paper

Springer is a part of Springer Science+Business Media

springer.com 


\section{Preface}

In recent years nobody could have failed to notice the frequent and often sensationalist media headlines warning of the latest global disease threat to humankind. But behind all the hyperbole lie real challenges related to dealing with the increasing incidence of emerging zoonotic disease events, the majority of which are thought to originate in wildlife (Jones et al. 2008). There are also many important diseases of domestic livestock which also occur in wildlife (e.g. foot and mouth disease and classical swine fever in wild boar, bovine tuberculosis in deer, badgers or possums), some of which can have a devastating impact on the farming industry, the wider rural economy and ultimately the public purse. But we should also not forget that wildlife diseases may have serious implications for the conservation of biodiversity. For some of the rarest, most endangered species (such as the Ethiopian wolf) disease may pose the greatest threat to their survival. If we are to avoid or reduce these impacts then we must improve our ability to detect and manage the risks associated with disease in wildlife populations. This is a challenge that will require expertise from many different disciplines: veterinary, ecological, medical, economic, political and zoological. In such an interdisciplinary field it is difficult to stay up to date with contemporary ideas and with techniques that may be rapidly evolving. We hope that in some small way this book contributes to informing people from a range of disciplines on our current state of knowledge and potential future directions in the management of disease in wildlife.

Largely because of our personal interests and expertise we have focused in this book on disease in wild mammals, although much that is discussed will be relevant to other wild fauna. Our aim has been to present and discuss the main issues related to disease management in wild mammals, and in doing so we have inevitably drawn upon the opinions of experts in a range of fields. We have attempted to be as inclusive as possible, in the knowledge that this is a topic at the interface between several scientific disciplines. We also acknowledge the important role that scientific knowledge plays in underpinning policy, and have therefore produced a text that is hopefully also accessible to those without a scientific training, but who are nevertheless important players in the development and implementation of disease management plans.

The editors have worked in the field of wildlife diseases for many years and whilst we maintain interests in other fields we continue to have close links with 
each other, particularly in the area of bovine tuberculosis in wildlife. We have seen at first hand how opinions change over time (albeit slowly in some cases), and how this process depends on the views and foresight of a wide diversity of experts. We have thus sought to include the opinions of many additional experts in different fields and would formally like to acknowledge their invaluable contributions. The co-authors not only gave generously of their time and expertise in helping to write individual chapters, but in many cases also improved the book by commenting on and correcting errors throughout the text. In addition we would like to thank Fred Landeg, Hamish McCallum, Menna Jones, Pete Robertson and Robbie McDonald for reviewing parts of the text and giving us additional perspectives. GCS and RJD would also like to thank Chris Cheeseman for his support and enthusiasm over the years. Many of the authors are involved in the Wildlife Disease Association and in particular with the European Section and we wish to collectively acknowledge the important contributions this organisation has made to promoting scientific endeavour in this field. 


\section{Contents}

1 The Science of Wildlife Disease Management..................................... 1

Richard J. Delahay, Graham C. Smith, and Michael R. Hutchings

2 Wildlife Population Structure and Parasite Transmission:

Implications for Disease Management.

Paul C. Cross, Julian Drewe, Victoria Patrek, Gareth Pearce,

Michael D. Samuel, and Richard J. Delahay

3 Assessment of Transmission Rates and Routes, and the Implications for Management

Peter Caley, Glenn Marion, and Michael R. Hutchings

4 Modelling Disease Dynamics and Management Scenarios

Graham C. Smith, Glenn Marion, Steve Rushton, Dirk Pfeiffer, Hans H. Thulke, Dirk Eisinger, and Michael R. Hutchings

5 An Economic Perspective on Wildlife Disease Management

Richard Bennett, Graham C. Smith, and Ken Willis

6 Options for the Control of Disease 1: Targeting the Infectious or Parasitic Agent

Jean Blancou, Marc Artois, Emmanuelle Gilot-Fromont, Volker Kaden, Sophie Rossi, Graham C. Smith, Michael R. Hutchings, Mark A. Chambers, Steve Houghton, and Richard J. Delahay

7 Options for the Control of Disease 2: Targeting Hosts Stephen P. Carter, Sugoto S. Roy, Dave P. Cowan, Giovanna Massei, Graham C. Smith, Weihong Ji, Sophie Rossi, Rosie Woodroffe, Gavin J. Wilson, and Richard J. Delahay 
8 Options for the Control of Disease 3: Targeting the Environment

Alastair I. Ward, Kurt C. VerCauteren, W. David Walter, Emmanuelle Gilot-Fromont, Sophie Rossi, Gareth Edwards-Jones, Mark S. Lambert, Michael R. Hutchings, and Richard J. Delahay

9 Risk Assessment and Contingency Planning for Exotic Disease Introductions

Vicky S. Jackson, Selene Huntley, Alex Tomlinson,

Graham C. Smith, Mike A. Taylor, and Richard J. Delahay

10 Wildlife Disease Surveillance and Monitoring

Marc Artois, Roy Bengis, Richard J. Delahay, Marie-José Duchêne, J. Paul Duff, Ezio Ferroglio, Christian Gortazar, Michael R. Hutchings, Richard A. Kock, Frederick A. Leighton, Torsten Mörner, and Graham C. Smith

11 Disease Management in Endangered Mammals

Andrew C. Breed, Raina K. Plowright, David T. S. Hayman,

Darryn L. Knobel, Fieke M. Molenaar, David Gardner-Roberts, Sarah Cleaveland, Dan T. Haydon, Richard A. Kock, Andrew A. Cunningham, Anthony W. Sainsbury, and Richard J. Delahay

Glossary

References.

Index 


\section{Contributors}

\section{Marc Artois}

Université J. Fourier, Laboratoire TIMC-IMAG, Unité Environnement et Prévision de la Santé des Populations F-38000 Grenoble; Ecole Nationale Vétérinaire de Lyon, France

\section{Roy Bengis}

Veterinary Investigation Centre, P.O. Box 12, Skukuza 1350, South Africa

\section{Richard Bennett}

School of Agriculture, Policy and Development, University of Reading, Reading, RG6 6AR, UK

\section{Jean Blancou}

11, rue Descombes 75017 Paris, France

\section{Andrew C. Breed}

School of Veterinary Science, Australian Biosecurity Cooperative Research Centre, University of Queensland, Brisbane, Australia

\section{Peter Caley}

National Centre for Epidemiology \& Population Heath, Australian National University, ACT 0200, Australia

\section{Stephen P. Carter}

Central Science Laboratory, Sand Hutton, York, YO41 1LZ, UK

\section{Mark A. Chambers}

TB Research Group, Department of Statutory and Exotic Bacterial Diseases, Veterinary Laboratories Agency, Weybridge, New Haw, Addlestone, Surrey, KT15 3NB, UK

\section{Sarah Cleaveland}

The Roslin Institute/Royal (Dick) School of Veterinary Studies, University of Edinburgh, Easter Bush, Roslin, Midlothian, EH25 9RG, UK

\section{Dave P. Cowan}

Central Science Laboratory, Sand Hutton, York, YO41 1LZ, UK 


\section{Paul C. Cross}

U.S. Geological Survey, Northern Rocky Mountain Science Center, 229 AJM Johnson Hall, Bozeman MT 59717, USA, and Montana State University, Department of Ecology, Bozeman MT, USA

\section{Andrew A. Cunningham}

Institute of Zoology, Zoological Society of London, Regent's Park, London, NW1 4RY, UK

\section{Richard J. Delahay}

Central Science Laboratory, Sand Hutton, York, YO41 1LZ, UK

\section{Julian Drewe}

Wildlife Health and Conservation Medicine Group, Department of Veterinary Medicine, University of Cambridge, Madingley Road, Cambridge, CB3 0ES, UK

\section{Marie-José Duchêne}

AFSSA LERRPAS, Technopôle Agricole et Vétérinaire, B.P. 40009, 54220 Malzéville, France

\section{J. Paul Duff}

Veterinary Laboratories Agency Diseases of Wildlife Scheme (VLADoWs), VLA Penrith, Penrith, Cumbria, CA11 9RR, UK

\section{Gareth Edwards-Jones}

School of the Environment and Natural Resources, University of Wales, Bangor, Gwynedd, LL57 2UW, UK

\section{Dirk Eisinger}

Helmholtz Centre for Environmental Research - UFZ, Permoserstraße 15, D-04318 Leipzig, Germany

\section{Ezio Ferroglio}

Dipartimento Produzioni Animali, Epidemiologia ed Ecologia Via Leonardo da Vinci, 44-10095 Grugliasco (TO), Italy

\section{David Gardner-Roberts}

The Mountain Gorilla Veterinary Project, BP 105 Musanze District, North Province, Rwanda

\section{Emmanuelle Gilot-Fromont}

Université de Lyon; Université Lyon 1; CNRS;UMR5558, Laboratoire de Biométrie et Biologie Evolutive, 43 Boulevard du 11 Novembre 1918, Villeurbanne F-69622, France

\section{Christian Gortazar}

Instituto de Investigación en Recursos Cinegéticos IREC (CSIC-UCLM-JCCM), Ronda de Toledo s.n. E-13071, Ciudad Real, Spain 


\section{Dan T. Haydon}

Department of Environmental and Evolutionary Biology, Graham Kerr Bldg, University of Glasgow, Glasgow, Scotland, G12 8QQ, UK

\section{David T. S. Hayman}

Cambridge Infectious Diseases Consortium, University of Cambridge,

Cambridge, CB3 OES, UK

\section{Steve Houghton}

Veterinary Vaccines Consultancy, Coles Cottage, Plum Park Lane,

Paulerspury, Northants, NN12 7NN, UK

\section{Selene Huntley}

Central Science Laboratory, Sand Hutton, York, YO41 1LZ, UK

\section{Michael R. Hutchings}

SAC, West Mains Road, Edinburgh, EH9 3JG, UK

\section{Vicky S. Jackson}

Central Science Laboratory, Sand Hutton, York, YO41 1LZ, UK

\section{Weihong Ji}

Massey University, Albany, Private Bag 102 904, North Shore Mail Centre, Auckland, New Zealand

\section{Volker Kaden}

Friedrich-Loeffler-Institut, Bundesforschungsinstitut für Tiergesundheit, Institut für Infektionsmedizin, 17493 Greifswald-Insel Riems, Germany

\section{Darryn L. Knobel}

The Roslin Institute/Royal (Dick) School of Veterinary Studies, University of Edinburgh, Easter Bush, Roslin, Midlothian, EH25 9RG, UK

\section{Richard A. Kock}

Conservation Programmes, Zoological Society of London, Regent's Park, London, NW1 4RY, UK

\section{Mark S. Lambert}

Central Science Laboratory, Sand Hutton, York, YO41 1LZ, UK

\section{Frederick A. Leighton}

Canadian Cooperative Wildlife Health Centre, Department of Veterinary

Pathology, University of Saskatchewan, Saskatoon, Saskatchewan S7N 5B4, Canada

\section{Glenn Marion}

Biomathematics Statistics Scotland, The Kings Buildings, Edinburgh, EH9 3JG, UK

\section{Giovanna Massei}

Central Science Laboratory, Sand Hutton, York, YO41 1LZ, UK 


\section{Fieke M. Molenaar}

Institute of Zoology, Zoological Society of London, Regent's Park, London, NW1 4RY, UK

\section{Torsten Mörner}

National Veterinary Institute, 75189 Uppsala, Sweden

Victoria Patrek

Montana State University, Department of Ecology, Bozeman MT, USA

\section{Gareth Pearce}

Wildlife Health and Conservation Medicine Group, Department of Veterinary Medicine, University of Cambridge, Madingley Road, Cambridge, CB3 0ES, UK

\section{Dirk Pfeiffer}

The Royal Veterinary College, London, Hawkshead Lane, North Mymms, Hatfield, Hertfordshire, AL9 7TA, UK

\section{Raina K. Plowright}

Consortium for Conservation Medicine, 460 West 34th Street, New York, NY 10001, USA

\section{Sophie Rossi}

Unité Sanitaire de la Faune, Micropolis, la Bérardie, Belle Aureille, 05000 GAP, France

\section{Sugoto S. Roy}

Central Science Laboratory, Sand Hutton, York, YO41 1LZ, UK

\section{Steve Rushton}

University of Newcastle upon Tyne, Newcastle upon Tyne, NE1 7RU, UK

\section{Anthony W. Sainsbury}

Institute of Zoology, Zoological Society of London, Regent's Park, London, NW1 4RY, UK

\section{Michael D. Samuel}

U.S. Geological Survey, Wisconsin Cooperative Wildlife Research Unit, University of Wisconsin, Madison, WI 53706, USA

\section{Graham C. Smith}

Central Science Laboratory, Sand Hutton, York, YO41 1LZ, UK

\section{Mike A. Taylor}

Central Science Laboratory, Sand Hutton, York, YO41 1LZ, UK

\section{Hans H. Thulke}

Helmholtz Centre for Environmental Research - UFZ, Permoserstraße 15, D-04318 Leipzig, Germany

\section{Alex Tomlinson}

Central Science Laboratory, Sand Hutton, York, YO41 1LZ, UK 


\section{Kurt C. VerCauteren}

USDA, APHIS, Wildlife Services, National Wildlife Research Center,

Fort Collins, CO, USA

\section{W. David Walter}

USDA, APHIS, Wildlife Services, National Wildlife Research Center,

Fort Collins, CO, USA

\section{Alastair I. Ward \\ Central Science Laboratory, Sand Hutton, York, YO41 1LZ, UK}

\section{Ken Willis}

School of Architecture, Planning and Landscape, University of Newcastle, NE1 7RU, UK

\section{Gavin J. Wilson}

Central Science Laboratory, Sand Hutton, York, YO41 1LZ, UK

\section{Rosie Woodroffe}

Institute of Zoology, Zoological Society of London, Regent's Park, London, NW1 4RY, UK 